\title{
Optical coherent control in semiconductors
}

\section{Østergaard, John Erland; Vadim, Lyssenko; Hvam, Jørn Märcher}

\section{Published in:}

Summaries of Papers Presented at the Technical Digest Quantum Electronics and Laser Science Conference

Link to article, DOI:

10.1109/QELS.2001.962055

Publication date:

2001

\section{Document Version}

Publisher's PDF, also known as Version of record

Link back to DTU Orbit

\section{Citation (APA):}

Østergaard, J. E., Vadim, L., \& Hvam, J. M. (2001). Optical coherent control in semiconductors. In Summaries of Papers Presented at the Technical Digest Quantum Electronics and Laser Science Conference https://doi.org/10.1109/QELS.2001.962055

\section{General rights}

Copyright and moral rights for the publications made accessible in the public portal are retained by the authors and/or other copyright owners and it is a condition of accessing publications that users recognise and abide by the legal requirements associated with these rights.

- Users may download and print one copy of any publication from the public portal for the purpose of private study or research.

- You may not further distribute the material or use it for any profit-making activity or commercial gain

- You may freely distribute the URL identifying the publication in the public portal 
Optical coherent control in semiconductors

John Erland, Vadim G. Lyssenko, and

Jorn M. Hvam, Research Center COM, Technical

University of Denmark, Oersteds Plads 349,

Dk-2800 Kgs. Lyngby, Denmark Email:

jeo@com.dtu.dk

The developments with coherent control (CC) techniques in optical spectroscopy have recently demonstrated population control and coherence manipulations when the induced optical phase is explored with phase-locked laser pulses. Fascinating demonstrations were first obtained with atoms and molecules such as localization of electronic wavepackets in atomic sodium and contro of molecular chemical reactions. ${ }^{1,2}$ These and other developments have been guiding the new research field of quantum control including the recent applications to semiconductors and nanostructures. Examples include population control of excitons in GaAs quantum wells and quantum dots as well as control of electronphonon scattering is GaAs that have provided new advancements in ultrafast spectroscopy of semiconductors. $^{3-5}$
We study the influence of inhomogeneous broadening in semiconductors on $\mathrm{CC}$ results. Photoluminescence (PL) and the coherent emission in four-wave mixing (FWM) is recorded after resonant excitation with phase-locked laser pulses with wave vector $k_{1}$. For the FWM, a second beam with wave vector $k_{2}$ is incident on the sample resulting in the coherent scattering of the emission in the direction $2 k_{2}-k_{1}$, see Fig. la. The sample is a narrow $28 \AA$ GaAs single quantum well (SQW), surrounded by $250 \AA$ $\mathrm{Al}_{0.3} \mathrm{Ga}_{0.7} \mathrm{As}$ barriers, grown by molecular-beamepitaxy with growth-interruptions on the barrier-well interfaces. This leads to formation of large monolayer-plane islands with 11 monolayers (ML) thickness; see sample characterization in Fig. 1b. Our main experimental results are shown in Fig. 1c and Fig. 1d with the spectrally resolved FWM. In the direction of observation for the FWM signal, we simultaneously record PL from the sample on the low-energy side. The strong fringes, corresponding to the optical period, of these optical signals are caused by the interference between the two polarizations excited by the phase-locked CC laser pulses. The striking difference in the time-delay dependence is evident from Fig. Ic at zero delay with no spectral

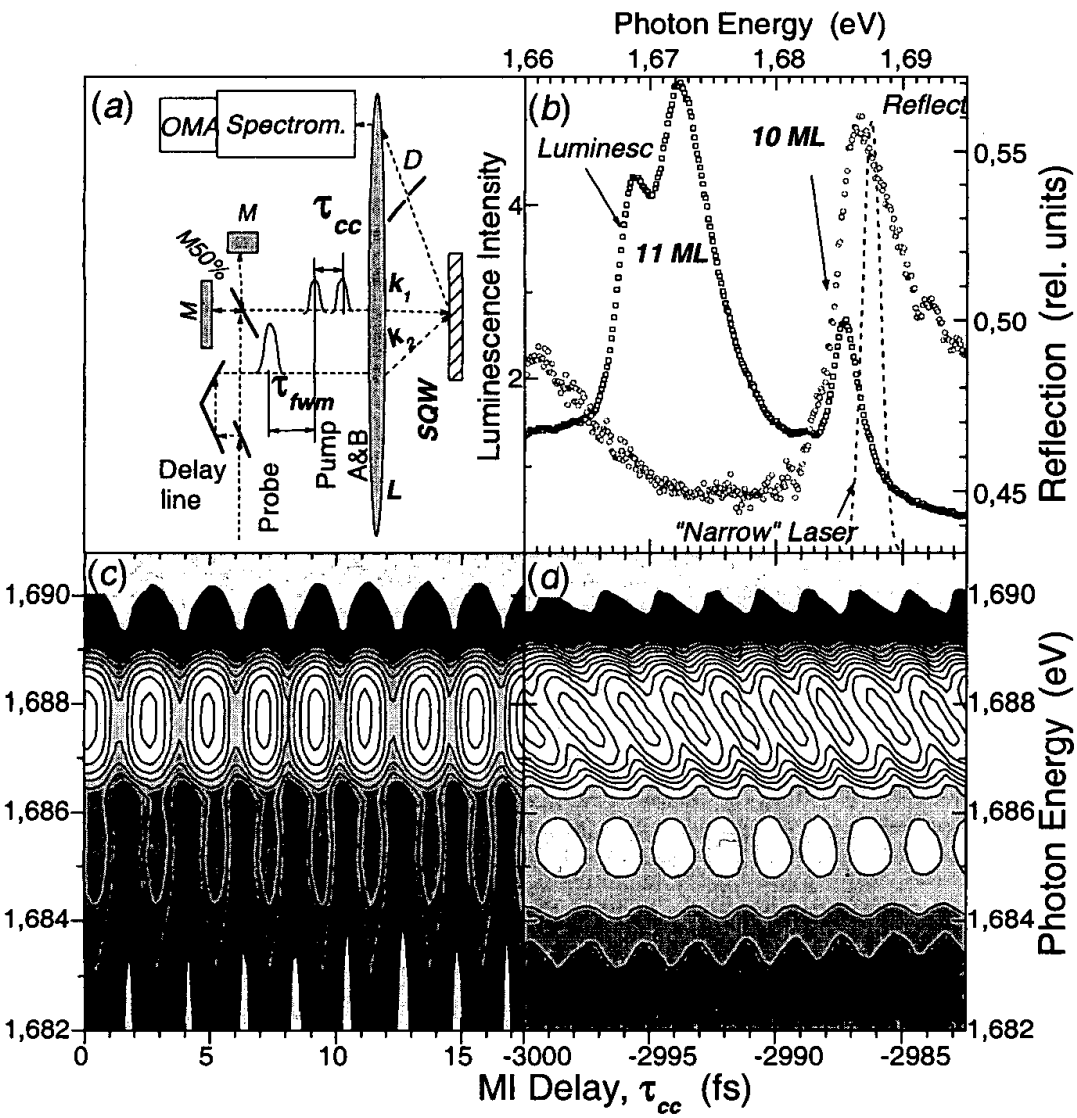

QThG2 Fig. 1. a) Experimental setup with a Michelson interferometer for phase-locked pulse pair generation with time-delay $\tau_{\mathrm{CC}}$. The FWM, generated by a time-delayed $\left(\tau_{\mathrm{fwm}}\right)$ third pulse, is spectrally resolved and detected with an optical multichannel analyzer (OMA). b) Luminescence (squares) and reflection (circles) of the GaAs SQW revealing two regions with thickness of 11 and 10 monolayers. The pump laser spectrum is snown dashed. c,d) FWM-spectra at $12 \mathrm{~K}$ with PL $(\nabla \omega<1.686 \mathrm{eV})$ for different phase delay $\tau_{C C}=0$ and $\tau_{C C}=-3$ ps with $\tau_{\mathrm{fwm}}=0.5 \mathrm{ps}$. variation of the PL and FWM signals, whereas for longer phase delay in Fig. 1(d), the fringes in the FWM acquires a phase, dependent on the detected photon energy $\omega$. For the latter, the PL signal appears to be proportional to the spectrally integrated FWM signal i.e. without any spectral variation.

Calculations of the FWM signal in the twolevel approximation using $\mathrm{CC}$ pulses give an explanation of the spectral behavior of CC experiments in inhomogeneously broadened semiconductors. For large inhomogeneous broadening $\left(\Gamma \gg \gamma_{21}\right)$, we show in Fig. 2(a) that the different spectral components have different phase within the chosen spectral window. In the other limit $(\Gamma$ $\sim \gamma_{21}$ ), the FWM CC fringes have no spectral variation as shown in Fig. 2(f). However, in-between these two limits we find that the spectral wings of the FWM spectra have the same phase whereas an increasing part of the center acquires the phase change. This occurs as a result of the mixing of the Lorentzian part due to the homogeneous broadening, with constant phase $\omega_{21} \tau_{\mathrm{CC}}$ and the Gaussian part with phase $\omega \tau_{\mathrm{CC}}$ due to the inhomogeneous broadening. This explains how inhomogeneous broadening influences $\mathrm{CC}$ experiments and in particular how the fringe contrast decay change with inhomogeneous broadening.

\section{References}

1. J.A. Yeazell, and C.R. Stroud Jr., "Observation of spatially localized atomic electron wave packets," Phys. Rev. Lett. 60, 1494 (1988).

2. W.S. Warren, H. Rabitz, and M. Dahleh, "Coherent control of quantum dynamics: the dream is alive", Science 259, 1581 (1993).

3. A.P. Heberle, J.J. Baumberg, and K. Köhler, "Ultrafast coherent control and destruction of excitons in quantum wells," Phys. Rev. Lett. 75, 2598 (1995).

4. N.H. Bonadeo, J. Erland, D. Gammon, D. Park, D.S. Katzer, and D.G. Steel, "Coherent Optical Control of the Quantum State of a Single Quantum Dot", Science 282, 1473 (1998).

5. M.U. Wehner, M.H. Ulm, D.S. Chemla, and M. Wegener, "Coherent Control of ElectronLO-Phonon Scattering in Bulk GaAs," Phys. Rev. Lett. 80, 1992 (1998).

QThG3

$$
\text { (Invited) }
$$

$11.00 \mathrm{am}$

Signatures of carrier-wave Rabi flopping in GaAs

O.D. Mücke, T. Tritschler, and M. Wegener, Institut für Angewandte Physik, Wolfgang-Gaede-Straße 1, Universität Karlsruhe (TH), 76131 Karlsruhe, Germany; Email: martin.wegener@physik.uni-karlsruhe.de

U. Morgner and F.X. Kärtner, Institut für Hochfrequenztechnik und Quantenelektronik Universität Karlsruhe (TH), 76131 Karlsruhe, Germany

Illuminating a semiconductor with a constant light intensity can lead to a periodic oscillation of the inversion, a phenomenon which is known as Rabi flopping. Using pulsed excitation, Rabi flopping has been observed on semiconductors ${ }^{1-3}$ and exhibited periods in the range from 100 fs to 1 ps. What happens if the light intensity becomes so 